\title{
Life of an Obstetrician and Gynaecologist: A 45 Years Journey
}

\author{
C. N. Purandare ${ }^{1}$
}

Received: 13 April 2020 / Accepted: 15 April 2020 / Published online: 12 May 2020

(c) Federation of Obstetric \& Gynecological Societies of India 2020

\section{Editorial note:}

I am extremely pleased to present this guest editorial by Professor C. N. Purandare, a beloved teacher, who has been the guiding force not only to me but to so many of his students and colleagues. He is one of the illustrious past editors of this journal. When I requested him to write an editorial on what it takes to be the FIGO president and a successful obstetrician and a gynaecologist, he was more than happy to share his thoughts. He has penned down his memorable journey of more than four decades. I am sure it will be of immense interest to readers. Here I present pearls of wisdom from an obstetrician and gynaecologist with a 45 years of experience and command!

-Professor Suvarna Khadilkar, Editor in chief.

"You can't do anything about the length of your life, but you can do something about its width and breadth"-Evan Esar

A Doctor's life is a fascinating journey of several ups and downs, of feelings, making a difference in the lives of those who have placed their precious lives in your hands, because your hands are the ones that give hope, heal and spread happiness. It's invigorating, more so in the life as an obstetrician and gynaecologist, as one deals with the two lives of the baby and mother. I joined the profession by choice, as I come from a family which has a background where we talked and walked obstetrics all the time, shared motivating stories about the profession thus it constantly kept encouraging me to be a part of the same fraternity.

Prof C. N. Purandare is a Consultant, Obstetrician and Gynaecologist, Purandare Hospital Mumbai India, Mumbai Police, Hon. Consultant, Saifee Hospital \& BSES Hospital, Mumbai. He is also a Visiting consultant at St. Elizabeth Hospital Mumbai.

C. N. Purandare

dr.c.n.purandare@gmail.com

1 Mumbai, India
Gynaecology and Obstetrics (OBGYN) are the two sides of the same coin, while former is considered a science, the latter an art. One can carry on work as a gynaecologist where the formula of one plus one is equal to two works; however, the same cannot be true for work as an obstetrician, given that there are many real-time variables to keep up with. Decision making in Gynaecology can wait for a week, while the surgeon consults his peers, books and can expedite the procedure; however, in Obstetrics, one needs to take split second decisions and must have the required expertise to act on immediately. One cannot tell the patient in labour that we can wait and do normal delivery or do a forceps or vacuum or caesarian by thinking about it or consulting evidence and come back to do it tomorrow. It is a $24 \times 7$ job with no exceptions; action has to be taken right then and there!

At a tender age of fourteen, I was in awe of my grandfather Dr. N. A. Purandare, who influenced my decision to do medicine and then OBGYN.

I started my career as an obstetrician; training, practicing, teaching and knowing that it's a long journey and knew that it was going to be tedious journey. The unique experiences and life's lessons moulded me to be a better doctor, individual and human being as this profession needs compassion, understanding and empathy.

Maternal and perinatal mortality can never be zero, and we have to deal with situations of both happiness and sadness. Pregnancy and its outcome are considered by the mother and the family as a happy event to be celebrated, but at the same time a loss of life for a family can be devastating, and an obstetrician has to be in the forefront to explain the loss which is a herculean task in itself.

Little do the patients and their relatives realize that pregnancy is not a simple natural process with always a happy ending (although we always strive for the same), things can go wrong within minutes. All this gives an obstetrician tremendous mental stress. Anything more than 200-300 per year deliveries for an obstetrician is a physical, mental and emotional nightmare. In India, 37,000 obstetricians need each single one to deliver or supervise average 800 deliveries. 
Gone are the days when women had numerous pregnancies. Today with small families everyone is expecting a healthy baby who would be a future Einstein in adult life. Any disability which can occur congenitally or during the process of labour is not acceptable leave aside death.

Faith in doctors has eroded due to the day-to-day life experiences patients have had and one feels that everyone around them is set to cheat and make money as making money is the entire population's ultimate goal. Honesty, integrity and ethics have taken a back seat in the social structure world over.

World over some lawyers advertise how they can extract money from the doctors and institutions at a percentage sharing with patients putting pressure on doctors to practise defensive Obstetrics. Whichever way you may deliver, vaginally, instrumental delivery or Caesarian, the doctor is sued resulting in majority of newly qualified doctors shying away from being an obstetrician. The Art of Obstetrics is not dying but nearly dead!

On the one side, society is screaming that there are too many Caesarian sections, but at the same time Obstetric practice has changed from delivering a young 25 year old or less women to a high risk 35 years plus women, many of them with medical problems and IVF pregnancies.

It is said that the last $10-\mathrm{cm}$ journey through the birth canal is one of the most difficult journeys that a human being ever undertakes in their life. It is this journey that an obstetrician facilitates with all the experience and skill.

A time will come when no one, patients or doctors alike would like to take a chance of a normal delivery and like we see in private sector of Brazil nearly $90 \%$ will be Caesarian deliveries and the remaining being accidental vaginally deliveries because no one was around.

Our years of training are mentally, physically strenuous. I remember getting up at 5 a.m. to do the ward round with 90 patients, many of them on the floor between beds and also under the bed what had to be seen in $2 \mathrm{~h}$ before the registrar came for his round.

Further twice a week it was an overnight duty delivering a dozen patients between two house officers.

I vividly remember few interesting and funny episodes of those golden days; the entire unit residents waiting in the evening of our emergency Sunday for the freshly cooked meal being brought from my home which was shared.

A patient undergoing a surgical termination of pregnancy was reluctant to get an IUCD fitted for contraception and when probed she said she would be careful as this accident happened because it was her husband's birthday.

A patient was asked to bring a stool sample for check-up the next week and landed up with a whole week's stools packed in a Dalda container.

I had some extraordinary colleagues and seniors making the journey during training worthwhile in the end. I cannot but not mention Dr. E. J. Sequiera, Dr. Sharad Nanavati, Dr. S. S. Thakur from Nair hospital, Dr. G. B. Belvi from Bhagwati hospital Borivali and Dr. Fergus Meehan from Galway Ireland under whom I trained. Each one of them moulded me and taught me different facets in life and the profession. Dr. Sequiera taught me to fight battles with your own generation and not take them to the next, Dr. Thakur as my PG teacher, to put the best foot forward and aim to be the best, Dr. G. B. Belvi gave me experience and confidence as a surgeon and Dr. Fergus Meehan, confidence to be on par with everyone and anyone. These facets eventually helped me to be what I achieved in the end.

The 4 years I spent in Ireland were the turning point in my life, from a shy and scared of senior's kind of an individual; I blossomed into a confident, articulate obstetrician ready to face the world. Galway taught me to treat my juniors as colleagues and friends, the fruits of which I see and enjoy even today.

Today's obstetrician and gynaecologist has become a multitasking multispecialist with high stress levels. One who has to bear the stress of routine day-to-day work, monetary, setting up of practice, medico legal, family needs, peers, seniors and head of the departments who in this day and age treat their colleagues and juniors like slaves or subordinates to be harassed and trampled over.

I remember that in the past, one angry look of Dr. K. K. Deshmukh at JJ Hospital without a spoken word used to be enough for residents not to repeat the same mistake again. You cannot demand respect, but you have to earn it and she really did.

Going forward, I urge my colleagues to utilize their spare time to read books, play games, experience simple things in life, do whatever you want, whenever you want and let go of your inhibitions, cool you off by looking for affection from family and friends, eat well as the next meal time can't be guaranteed, catch your forty winks when you get a chance, shower affection or appreciation to your juniors when they deserve it and love your family members as they are the shining stars in your life.

My tenure of 20 years in JJ Hospital as the Honorary Professor of Obstetrics and Gynaecology was extremely satisfying as I taught thousands of undergraduate students and hundreds of postgraduate students. They all became my true friends and supporters for life, and I am indebted to them.

My progress professionally in organizations like Mumbai Obstetric and Gynaecological Society, The Federation of Obstetrics and Gynaecological Societies of India in various capacities for 20 years and ultimately the highest honour to represent India as President of FIGO have been very humbling, I have no hesitation in dedicating this to all my seniors, peers, students who gave me the support, love and affection and continue to do so. 
Government decision to remove honorary teachers and keeping full time ones sadly brought the great institutions like Grant Medical College to mediocrity.

Teachers who were fortunate to work in both private as well as public sectors acquired iconic stature. These honorary teachers would impart high level training to students and budding gynaecologists. During my tenure as a honorary in Grant Medical College, we onetime boasted of many such iconic personalities in different departments of the college, like Dr. Farouk Udwadia, Dr. Tehmton Udwadia, Dr. B. K. Goyal, Dr. B. S. Singhal, Dr. Vasant Patwardhan, Dr. Usha Saraiya, Dr. Tulpule, Dr. O. P. Kapoor, Dr. Altaf Patel, Dr. Jairam, Dr. Vasant Jaykar to name a few on the panel. I am happy to note that MCI has realized the damage done and is in the process of reversing the decision.

I always told my students being successful is more important than standing first in a class. In life you can't win all battles, winning and being successful are different entities. When you progress in life, you will have enemies and their jealousy will not let you prosper. Politics is in every field therefore focus and fight only those battles which matter and not all which will sap your time and energy.

As Sir Winston Churchill said "You have enemies? Good. That means you have stood up for something in your life".

"Get happiness out of your work or you may never know what happiness is". "Elbert Hubbard".

Live life that matters

\section{About the Author}

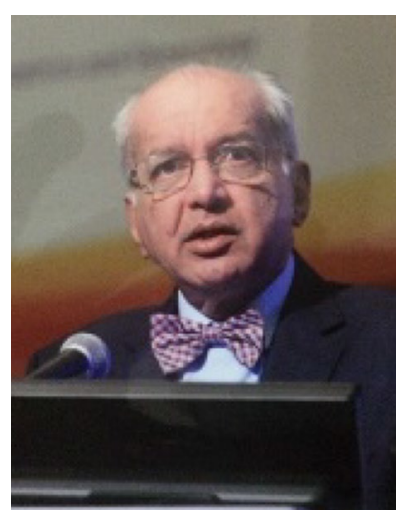

Prof C. N. Purandare is a Consultant, Obstetrician and Gynaecologist, Purandare Hospital Mumbai India, Mumbai Police, Hon. Consultant, Saifee Hospital \& BSES Hospital, Mumbai. He is also a Visiting consultant at St. Elizabeth Hospital Mumbai. He has held many prestigious positions like President FIGO (20152018), President, FOGSI (2009), President Indian College of OB GYN (2009) and Emeritus Dean Indian College of Obstetricians and Gynaecologist. He is Editor Emeritus, Journal OB GYN of India (JOGI), FOGSI. He was the Project Director, FOGSI-FIGO-B\& MGF-MNH Project, and Ex. Hon. Prof. OB GYN, Grant Medical College \& J J Hospital, Mumbai. Professor Emeritus O\&G Research institute Ministry of Health Russian Federation. 